\title{
CURRÍCULO EM SERVIÇO SOCIAL: CONSTRUÇÃO E DESAFIOS CONTEMPORÂNEOS
}

\author{
CURRICULUM IN SOCIAL WORK: CONSTRUCTION AND CONTEMPORARY \\ CHALLENGES
}

\begin{abstract}
R. F. C. de ANDRADE ${ }^{1, *}$, A. P. D. CORRÊA e R. R. GAMA²
1 Doutora e Mestre em Sociedade e Cultura na Amazônia pela Universidade Federal do Amazonas (UFAM), com graduação em Serviço Social pela mesma universidade. Líder do Grupo de Pesquisa Estudos de Sustentabilidade, Trabalho e Direitos na Amazônia - ESTRADAS, Coordenadora do Curso de Serviço Social da Universidade Federal do Amazonas.

2 Acadêmicas de Serviço Social pela Universidade Federal do Amazonas. Integrantes do Grupo de Pesquisa Estudos de Sustentabilidade, Trabalho e Direitos na Amazônia - ESTRADAS.
\end{abstract}

\section{ART I C LE IN F O \\ Article history: \\ Received 2018-04-13 \\ Accepted 2018-04-30 \\ Available online 2018-05-02 \\ ${ }^{*}$ Autor correspondente: \\ E-mail: roberta_ufam@yahoo.com.br}

Palavras-chave: currículo; Serviço Social; formação profissional; diretrizes curriculares; capitalismo.

Keywords: curriculum; Social Work; professional qualification; curricular guidelines; capitalism.

RESUMO. O objetivo deste artigo é problematizar o currículo como construção social, que direciona a formação profissional e deve estar conectado às necessidades e ao movimento da sociedade. Interessa-nos dar destaque à sua construção no âmbito do Serviço Social, uma profissão que se redesenhou ao longo de sua trajetória sócio-histórica na sociedade brasileira. A metodologia se sustenta nas pesquisas bibliográfica e documental, as quais nos permitem reconhecer que os conteúdos curriculares do Serviço Social já foram predominantemente influenciados por variadas correntes de pensamento, como o neotomismo, o positivismo, o funcionalismo e, atualmente, o marxismo. Na contemporaneidade, temos um currículo voltado para atender as demandas das classes subalternas, construído a partir da união da categoria de assistentes sociais, baseando-se no tripé que sustenta a profissão, a saber: Lei de Regulamentação da Profissão, Código de Ética Profissional do Assistente Social e Diretrizes Curriculares. No entanto, este currículo não está plenamente materializado, e tem sofrido diversos ataques, devido à tendência de mercantilização do ensino superior no atual contexto brasileiro. Esta tendência conduz à construção de um novo perfil de profissional, com uma formação mais restrita, mais técnica, mais instrumental, uma perspectiva que vai na contramão do projeto coletivamente construído pela categoria nos anos 1990.

\begin{abstract}
The purpose of this article is to problematize the curriculum as social construction, which directs the professional formation and must be connected to the needs and the movement of the society. We are interested in highlighting its construction in the scope of Social Work, a profession that has been redesigned throughout its socio-historical trajectory in Brazilian society. The methodology is based on bibliographical and documentary research, which allows us to recognize that the curricular contents of Social Work have already been predominantly influenced by different currents of thought, such as neotomism, positivism, functionalism and, currently, marxism. In contemporary times, we have a curriculum aimed at meeting the demands of the subaltern classes, built from the union of the category of social workers, based on the tripod that sustains the profession, namely: Law of Professional Regulation, Professional Code of Ethics Social Worker and Curricular Guidelines. However, this curriculum is not fully materialized, and has suffered several attacks, due to the trend of commercialization of higher education in the current Brazilian context. This trend leads to the construction of a new profile of professionals, with a more restricted, more technical and more instrumental formation, a perspective that goes against the project collectively built by the category in the 1990 s.
\end{abstract}




\section{INTRODUÇÃO}

O currículo passou a ser alvo de formulações teóricas a partir do processo de industrialização, quando o tema assumiu vital importância para o desenvolvimento do modelo capitalista que se instaurou após as Revoluções Industriais. Neste contexto, com a até então inédita necessidade de mão de obra minimamente qualificada, os conteúdos que compunham as estruturas curriculares das escolas começaram a receber uma atenção nunca antes a eles dedicada.

Atualmente, entendemos que a matriz curricular de uma instituição é fundamental para compreender os aspectos de aprendizagem dentro de um curso de graduação ou pós-graduação. Os currículos são os norteadores para a formação dos profissionais que objetivam inserir-se no mercado de trabalho. Por isso, sua estrutura não deve permanecer estagnada, podendo modificar-se e adequar-se às mudanças históricas e sociais do mercado de trabalho e à própria visão dos profissionais envolvidos em seu processo de criação.

O Serviço Social desenvolve-se no Brasil em um contexto de transformações econômicas e sociais, no qual passa a exigir-se da profissão uma maior qualificação técnica, inserindo o profissional na divisão sociotécnica do trabalho. A profissão que nasceu no Brasil em 1936 guarda muitas distinções à profissão que se tem no século XXI. Àquela época, tinha-se uma formação influenciada pela doutrina social da Igreja, pelo neotomismo e pelo higienismo. Nos últimos decênios do século $X X$, a profissão se redirecionou e construiu um novo projeto de profissão, que é laico e se sustenta na teoria social de Marx, acenando para uma profissão crítica, que atua nas dimensões investigativa e interventiva.

Justamente na última década do século $X X$ e na primeira do século $X X I$, vivenciou-se no Brasil um processo de intensa expansão e mercantilização do ensino superior, que se fez sentir também no Serviço Social, afetando diretamente o currículo dos cursos de ensino superior no país, visto que há uma forte tendência de construir uma formação para atender as demandas do mercado, que se pautam no tecnicismo, na imediaticidade, na racionalidade instrumental.

O Serviço Social brasileiro construiu nas décadas de 1980 e 1990 um novo projeto éticopolítico, que aponta para a constituição de um ethos profissional crítico, reflexivo, propositivo, identificado com a classe trabalhadora, ancorado nas Diretrizes Curriculares para os cursos de Serviço Social (ABEPSS, 1996), Lei de Regulamentação da Profissão (Lei Federal 8.662/1993) e Código de Ética Profissional (1993).

Tal projeto de profissão é uma bússola que orienta para um perfil de profissional que se quer construir, mas não é a garantia da efetividade dessa formação, visto que, com o processo de mercantilização e aligeiramento do ensino superior brasileiro, vê-se que há outros projetos em disputa, que não se voltam para a coletividade, a emancipação humana ou defesa da liberdade e da cidadania, mas se preocupam em garantir a empregabilidade, $\mathrm{O}$ atendimento das demandas imediatas do mercado, a instrumentalização irrefletida.

É importante salientar que esses projetos de formação em disputa encontram abrigo na legislação educacional, que flexibiliza o credenciamento das instituições, que dá "autonomia" para modificar a matriz curricular (a qual, no caso do Serviço Social, não significa necessariamente a obediência à proposta coletiva organizada pela Associação Brasileira de Ensino e Pesquisa em Serviço Social - ABEPSS, já que as diretrizes aprovadas pelo Ministério da Educação - MEC 
desvirtuaram a proposta coletiva encaminhada), que permite que instituições de ensino superior ofereçam apenas o ensino, sem a obrigatoriedade da oferta de pesquisa e extensão, dentre outras questões que conduzem a um empobrecimento da formação graduada nos vários campos de formação, inclusive no Serviço Social.

Nesse sentido, num cenário de avanço do mercado, com achatamento da carga-horária, diminuição do tempo de formação e flexibilização do ensino, mais do que nunca é necessário reafirmar o projeto de profissão coletivamente construído pela categoria e mais do que isso, dar a ele materialidade.

\section{POR QUE É NECESSÁRIO FALAR DE CURRÍCULO?}

Ainda é comum nos depararmos com discursos que restringem o currículo a um documento, um papel, uma grade, uma lista de disciplinas. O currículo não deixa de nos remeter a uma lógica de formação, a uma organização do processo de ensino/aprendizagem, mas não temos o direito de esquecer que ele é, antes de tudo, uma construção social, que traz consigo concepções de mundo, ideologias, escolhas, como ensina Sacristán (2013). Sua constituição não se dá de maneira neutra, imparcial, incólume às determinações sócio-históricas, ele traz em si correntes em disputa, projetos societários concorrentes, antagonismos que residem na vida social.

Por isso, é imprescindível que a composição curricular seja resultante de uma construção coletiva, com a participação dos diferentes sujeitos envolvidos no processo de ensino/aprendizagem. Não pode ser uma imposição daqueles que, supostamente, têm maior domínio ou conhecimento sobre currículo. Quem dá vida ao currículo não são apenas os professores, mas os discentes, os técnicos administrativos, a instituição de ensino como um todo, até porque,

o currículo em ato de uma escola não é outra coisa senão essa própria escola em pleno funcionamento, isto é, mobilizando todos os seus recursos, materiais e humanos, na direção do objetivo que é a razão de ser de sua existência (SAVIANI, 2016, p. 55).

Seguindo essa lógica, o currículo merece ser alvo de discussões, pesquisas e aprofundamentos que revelem sua função, suas potencialidades e limites, que apontem para as demandas sociais a que ele precisa responder.

Diversos estudos e teorias se dispuseram a explicar o significado do currículo, possuindo como ponto em comum a ideia de organização dos elementos que compõem o processo educativo. De modo geral, esta sistematização usualmente inclui as matrizes curriculares, com conteúdos disciplinares e suas cargas horárias, além das ementas de cada disciplina e os planos de ensino dos professores (LOPES; MACEDO, 2011). De acordo com Sacristán (2013), ao estabelecer níveis, exigências, tempos para as atividades e o que será ensinado, o currículo não deixa de ser um regulador das pessoas.

Este modelo de concepção curricular, na ótica de Lopes e Macedo (2011), faz com que o currículo, juntamente com a escola, sejam concebidos como aparatos de controle social. Desta forma, pode-se entender o currículo e a escola como responsáveis por um duplo papel no processo de continuidade da estrutura social. Por um lado, são elementos importantes do mecanismo de produção 
da mão de obra, considerando os conteúdos técnicos que são minuciosamente escolhidos para compor os programas curriculares. Por outro lado, são propagadores da ideologia dominante, visto que, além de práticos, os componentes selecionados possuem também um caráter teórico essencialmente ideológico.

No contexto educacional contemporâneo, o currículo continua sendo tema de debates e discussões. O entendimento reflexivo e crítico do currículo, de suas influências e de suas consequências é uma responsabilidade social e pedagógica. Neste sentido, não só os estudiosos da área devem dedicar-se a esta questão, mas a sociedade como um todo, representada pelos grupos e movimentos sociais protagonistas do cenário educacional, com destaque para a categoria dos educadores. Desta forma, será possível combater a tendência de que os currículos sejam construídos por "tecnocratas", os quais possuem uma visão antiquada e conservadora sobre o mesmo, priorizando apenas seus aspectos técnicos e práticos (MACEDO; MACEDO, 2012).

O currículo, tal como é construído na atualidade, constitui-se inevitavelmente em um dispositivo autoritário e excludente de educação, visto que seu processo de elaboração e implementação não é democrático. Quando os estudantes adentram o contexto escolar, os programas curriculares já foram determinados.

Por este motivo, é de extrema importância que as argumentações acerca do currículo não se fechem apenas na significação do termo, mas sim nas relações de poder que estão por trás destes significados. É preciso questionar quem seleciona os conteúdos curriculares, para qual público e por quais motivos. Neste sentido, torna-se fundamental que a sociedade se aproprie do tema, fazendo com que ele deixe de ser propriedade dos especialistas e abrindo caminho para a democratização do debate.

\section{TRAJETÓRIA DO CURRÍCULO EM SERVIÇO SOCIAL}

Em 1936, a primeira escola em Serviço Social é fundada em São Paulo pelo Centro de Estudo e Ação Social (CEAS), que tem como função organizar a Ação Católica (IAMAMOTO e CARVALHO, 2013). Ao crescer no seio do CEAS como um núcleo de estudos da Doutrina Social da Igreja, as ações são impulsionadas a partir dos princípios do cristianismo, o qual se preocupa com a formação social moral e técnica, estabelecendo que a formação profissional deveria vir acompanhada da "vocação", "personalidade", juntamente com o "conhecimento dos problemas sociais" e com técnicas adequadas (SÁ, 1995).

Segundo Aguiar (1995), tendo como principais influentes Leonardo Van Acker, Alexandre Correia, Padre Roberto Sabóia de Medeiros, Padre Leonel Franca, entre outros, as escolas em Serviço Social são pautadas na filosofia neotomista, seguindo as encíclicas da Igreja Católica. A filosofia tomista é fundada no século XIII por São Tomás de Aquino, voltando no século XIX na forma de neotomismo. Essa corrente filosófica chega ao Serviço Social por intermédio da Igreja Católica, tão presente nas origens da profissão. Marcada pelo pensamento de Aristóteles, o tomismo acredita no homem como ser racional, social e político, defendendo o Estado como necessário para atingir um bem-estar comum e acreditando que o mesmo representa uma autoridade que não deve deixar de garantir o respeito à Igreja, tendo o princípio da dignidade humana como prioridade.

Assim, as encíclicas postas pelos Papas Leão XIII, Pio X e Pio XI são colocadas nas diretrizes brasileiras (AGUIAR, 1995). Dessa forma, contribuiu-se para o não questionamento do 
Estado dentro do sistema capitalista nos primeiros anos do Serviço Social brasileiro, garantindo uma formação doutrinária e religiosa (SILVA, 1995).

Em relatório publicado pelo CEAS em 1936, o perfil profissional é desenhado a partir de um conteúdo programático com disciplinas que davam subsídios à formação teórica e técnica. O perfil profissional indicava que o Serviço Social deveria agir sobre a vida social e familiar para reajustar o indivíduo às novas condições socialmente estabelecidas e, se necessário, criar novas condições para que se atinja um bem-estar social.

Ao examinar os currículos das primeiras escolas, Vasconcelos (2000) identifica também a influência do movimento higienista na formação em Serviço Social, dada a presença de disciplinas da área da saúde e a preocupação com a higiene presente na formação e atuação dos primeiros assistentes sociais.

Entre as décadas de 30 e 60, quatro das convenções realizadas pela Associação Brasileira de Ensino de Serviço Social (ABESS), tiveram como eixo central a preocupação com a formação profissional, principalmente no que se refere à base doutrinária e a base técnica. Em 1946, a ABESS se organiza para regulamentar o ensino do Serviço Social brasileiro, apresentando as bases para a lei no $1.889 / 53$ e para o decreto no $35.311 / 54$.

O embate sobre o currículo nesse período dá-se em duas direções: pois de um lado havia escolas que eram favoráveis à regulamentação do ensino superior, e por outro, havia a necessidade de auxiliares sociais que seriam formados em um período de um ano, sem nenhuma regulamentação da profissão, no tempo mais curto de que um curso de ensino superior.

Até o final da década de 50, de acordo com Aguiar (1995), há presença da filosofia tomista associada à técnica norte-americana. A técnica norte-americana tem como principal orientação teórica o funcionalismo, uma perspectiva mais sistemática. Essa influência norte-americana apresenta-se por meio da aproximação entre as escolas brasileiras e as estadunidenses, através de convites para a direção de Escolas de Serviço Social, e pelo fato de os Estados Unidos ofertarem uma grande parcela de bolsas para alunos latino-americanos.

O reflexo da influência norte-americana e funcionalista no currículo de Serviço Social pode ser observado através das disciplinas que compunham o documento na época, conforme o Decreto no 35.311 de 02 de abril de 1954 que regulamenta a Lei no 1889, de 13 de junho de 1953:

Quadro 1 - Disciplinas dos cursos de Serviço Social em 1953

\begin{tabular}{|c|c|c|}
\hline 1은 Série & 2 Série & 3aㅗㄷㅏe \\
\hline $\begin{array}{l}\text { Sociologia; } \\
\text { Ética Geral; } \\
\text { Psicologia; } \\
\text { Estatística; } \\
\text { Noções de Direito; } \\
\text { Higiene e Medicina Social; } \\
\text { Introdução ao Serviço Social; } \\
\text { Serviço Social de Casos; } \\
\text { Servico Social de Grupos. }\end{array}$ & $\begin{array}{l}\text { Economia Social; } \\
\text { Legislação Social; } \\
\text { Ética Profissional; } \\
\text { Pesquisa Social; } \\
\text { Atividade de Grupo; } \\
\text { Organização Social } \\
\text { Comunidade. }\end{array}$ & $\begin{array}{l}\text { Administração de } \text { Obras } \\
\text { Sociais; } \\
\text { Organização Social da } \\
\text { Comunidade; } \\
\text { Pesquisa Social. }\end{array}$ \\
\hline
\end{tabular}

Fonte: Adaptado de: BRASIL, 1954. 
Com o fim da década de 1950, o Serviço Social brasileiro entra em processo de ruptura com a corrente neotomista (AGUIAR, 1995). Em relação ao plano de conteúdo, no período entre 1958 a 1975, este é marcado por uma decadência do existencialismo em favor do desenvolvimentismo, que se desdobrou no neopositivismo até chegar ao marxismo althusseriano (SÁ, 1995).

Na década de 1980-1990, de acordo com lamamoto (2015), a profissão aproxima-se da teoria social de Marx, a qual aponta para uma leitura crítico-dialética da realidade social, numa perspectiva de articulação da profissão à classe trabalhadora, à qual pertence e com a qual assume compromisso ético-político. É nesse espírito que a própria formação profissional é repensada, com a formulação de um currículo mínimo em 1982, que é revisado nos anos 1990 e dá origem às Diretrizes Gerais para o Curso de Serviço Social de 1996, num processo capitaneado pela Associação Brasileira de Ensino em Serviço Social (ABESS, que passa a ser Associação Brasileira de Ensino e Pesquisa em Serviço Social - ABEPSS em 1998).

Assim, a partir dos anos 1990, a profissão é direcionada pela Lei de Regulamentação da Profissão (Lei 86662/93), Código de Ética Profissional do Assistente Social (1993) e a Proposta de Diretrizes Gerais para o Curso de Serviço Social (1996). O currículo que anteriormente se encontrava preso ao teoricismo, politicismo e tecnicismo, por meio da vinculação a autores cujas teorias eram baseadas numa leitura do marxismo, passa a fundamentar-se na corrente marxiana como fonte primária de conhecimento. A partir dessa perspectiva, o Serviço Social considera a questão social como consequência das mudanças sócio-históricas e busca entender o profissional inserido na divisão sociotécnica do trabalho. Estabelecendo pela primeira vez no currículo a relação entre os fundamentos históricos, teóricos e metodológicos do Serviço Social.

Segundo Castro e Toledo (2012), o currículo na década de 1980 foi dividido em 2 partes: ciclo básico e profissionalizante. O ciclo básico incorporava o conhecimento da realidade por meio das organizações que apresentavam o contexto da sociedade e do Serviço Social, assim como o currículo anterior continha matérias como sociologia, psicologia, economia, antropologia, direito e legislação social, porém acrescentava as matérias: formação social, econômica e política do Brasil e filosofia. $\mathrm{O}$ ciclo profissionalizante encarregava-se do conhecimento sistemático da função social da intervenção do assistente social e as habilidades e estratégias quanto aos diferentes contextos institucionais. No quadro abaixo as matérias referentes ao ano de 1982:

Quadro 2 - Disciplinas nos cursos de Serviço Social em 1982

\begin{tabular}{|l|l|}
\hline \multicolumn{1}{|c|}{ Ciclo básico } & \multicolumn{1}{c|}{ Ciclo profissionalizante } \\
\hline Filosofia; & Teoria do Serviço Social; \\
Sociologia; & Metodologia do Serviço Social; \\
Psicologia; & História do Serviço Social; \\
Economia; & Desenvolvimento de comunidade; \\
Antropologia; & Política social; \\
Formação social, econômica e política do Brasil; & Administração em Serviço Social; \\
Direito e legislação social. & Pesquisa em Serviço Social; \\
& Ética profissional em Serviço Social; \\
& Planejamento social. \\
\hline
\end{tabular}

Fonte: Adaptado de: CASTRO e TOLEDO, 2012.

Apesar de todos os esforços investidos na implementação deste projeto de revisão curricular, as mudanças propostas pelo novo currículo não foram suficientes para acompanhar as mudanças 
ocorridas nos campos social, político e econômico da sociedade. Sendo assim, o currículo de 1982 já nasceu defasado e uma revisão do currículo e da formação profissional continuou sendo necessária.

Com isso, a categoria profissional mobilizou-se para promover diversas oficinas e debates, em variadas cidades do país, com o objetivo de coletivamente criar uma proposta curricular que estivesse apta a atender as demandas da sociedade naquela época.

Esta associação da categoria resultou na elaboração de diversos documentos, os quais abordavam pressupostos, diretrizes, metas e núcleos de fundamentação para o novo modelo curricular. Ao final do processo, toda essa produção foi convertida em um documento final, intitulado "Proposta nacional de currículo mínimo para o Curso de Serviço Social", o qual foi aprovado em uma assembleia geral da ABESS em 1996. Também em 1996 foi promulgada a Lei de Diretrizes e Bases (Lei 9394) para o ensino brasileiro, tornando bastante conveniente a implantação das novas diretrizes para os cursos de Serviço Social (ABESS, 1997).

A lógica curricular publicada pela Associação Brasileira de Ensino e Pesquisa em Serviço Social - ABEPSS (1996) estabeleceu o tripé do conhecimento por meio dos núcleos de fundamentação da formação profissional: núcleo de fundamentos teórico-metodológicos da vida social, núcleo de fundamentos da formação sócio-histórica da sociedade brasileira e o núcleo de fundamentos do trabalho profissional. A partir desses núcleos, foram definidas as matérias específicas, colocando no centro do currículo o Estágio Supervisionado e o Trabalho de Conclusão de Curso como obrigatórios para a obtenção de título de bacharel em Serviço Social.

Neste contexto, as diretrizes aprovadas pela categoria profissional em 1996 são norteadas por novos pressupostos da formação profissional, os quais priorizam a questão social como determinante do processo de trabalho dos assistentes sociais, considerando sempre os pressupostos sócio-históricos e teórico-metodológicos da profissão, além das particularidades brasileiras.

Nas diretrizes da ABEPSS (1996) são consideradas disciplinas básicas para os cursos de Serviço Social: Sociologia, Ciência Política, Economia Política, Filosofia, Psicologia, Antropologia, Formação sócio-histórica do Brasil, Direito, Política Social, Acumulação Capitalista e Desigualdades Sociais, Fundamentos Históricos e Teórico-Metodológicos do Serviço Social, Processo de Trabalho do Serviço Social, Administração e Planejamento em Serviço Social, Pesquisa em Serviço Social e Ética Profissional.

No entanto, segundo lamamoto (2014), este novo texto, aprovado pelos assistentes sociais e instituições organizadoras, em 1996, não possui valor legal. As diretrizes que legalmente orientam a formação profissional em Serviço Social no Brasil foram determinadas na Resolução no 15 , de 13 de março de 2002, pelo presidente da Câmara de Educação Superior. Estas diretrizes foram fruto do movimento de contrarreforma do ensino superior e caracterizam-se por ter um perfil mais adaptável aos interesses do mercado e, consequentemente, das instituições de ensino, desconsiderando os produtos dos debates e oficinas realizados na década de 1990. Com isso, o conteúdo passou a ser sujeito aos interesses de cada instituição de ensino, e tornou-se impossível garantir um conteúdo básico comum a todos os cursos de formação profissional (IAMAMOTO, 2014).

\section{DESAFIOS AO CURRÍCULO DE SERVIÇO SOCIAL}

lamamoto (2015) afirma que a década de oitenta foi um divisor de águas para o Serviço Social brasileiro. Impulsionados externamente pelas alterações sociais, políticas e econômicas 
recém-sucedidas na sociedade (como, por exemplo, a luta pela democracia, a defesa do Estado de direito e as mudanças ocorridas no mundo do trabalho), e internamente pela influência da teoria social crítica (inspirada na tradição marxista), os profissionais organizaram-se para realizar debates, de modo a manter a profissão atualizada e oferecer novas respostas profissionais correspondentes aos atuais processos de trabalho.

No ano de 1979, a então Associação Brasileira de Ensino de Serviço Social (ABESS) propôs um novo currículo mínimo para o curso de Serviço Social. Este currículo foi inovador, pois levou em conta aspectos do movimento de reconceituação profissional latino-americano e refutou algumas características do Serviço Social tradicional. A proposta foi aprovada pelo MEC em 1982 e constituiu um importante ponto de referência para as atuais diretrizes curriculares, propostas e revisadas pela ABESS na década de 90 (IAMAMOTO, 2014).

Tudo isso culminou num fortalecimento do projeto acadêmico-profissional do Serviço Social, caracterizado por mudanças na legislação que rege a profissão, no ano de 1993; pela aprovação do código de ética do Serviço Social, também no ano de 1993 e pela proposta e revisão de novas diretrizes curriculares nacionais, nos anos de 1996 e 1999, respectivamente. Essas últimas, sendo produto de um rico conjunto de debates locais, regionais e nacionais.

Porém, este processo de renovação e atualização do currículo mínimo e das diretrizes curriculares precisou e ainda precisa superar alguns obstáculos. Em relação ao currículo, este foi enfraquecido pelos novos modelos de educação superior, os quais priorizam a flexibilidade, trabalhando com muitas disciplinas não obrigatórias e as habilidades técnico-operativas. Foi necessária uma união imperativa da categoria, utilizando-se dos parâmetros legais regulamentadores da profissão, para que este modelo não fosse enraizado na formação acadêmica em Serviço Social àquela época.

Em relação às diretrizes curriculares, vários conteúdos foram cortados de seus textos, sendo substituídos por tópicos mais genéricos, o que causou grande dificuldade em se estabelecer uma base comum para o ensino da profissão no Brasil. Basicamente, ficava a critério das instituições de ensino decidir o que seria e o que não seria abordado durante a formação profissional, dependendo das exigências do mercado (IAMAMOTO, 2014).

Segundo lamamoto (2014), uma característica contemporânea da profissão é o constante crescimento do número de assistentes sociais, impulsionado pela propagação do ensino superior privado. Neste aspecto, o problema não é o número de profissionais aptos a atuar, mas sim a qualidade da formação que eles receberam, pois, como já mencionado, o interesse do setor privado de educação é acumular lucro, sem se preocupar em oferecer uma graduação de base sólida e unificada. Isto contribui para uma fragilização da profissão que, com uma formação precária, torna-se mais suscetível a atender os interesses do mercado, em detrimento da população subalterna, seu verdadeiro objetivo.

Outro aspecto que a autora aponta e inclusive faz eco à sua menção no texto já discutido, é a necessidade de aprofundamento no estudo dos fundamentos do Serviço Social, compreendendo os aspectos históricos, teóricos e metodológicos da trajetória. Além deste ponto, lamamoto (2014) também recomenda que se dê atenção à trajetória de formação da sociedade brasileira, à relação entre ética e pesquisa e ao estágio supervisionado. 


\section{CONCLUSÃO}

Os debates sobre o currículo em Serviço Social estão distantes de um fim, e um fim não seria possível, afinal o curso perderia se abandonasse sua característica principal: a força da discussão e do autoquestionamento de sua ciência. Como profissão questionadora e preocupada com as transformações no mundo do trabalho, o Serviço Social tem como característica norteadora um constante estudo da realidade social, histórica, econômica e política do contexto em que está inserido. E fazê-lo através de base curricular é a opção para a formação de profissionais críticos, que lutam por direitos pautados em seu código de ética e na lei de regulamentação da profissão.

Trata-se de um projeto de formação que reconhece que o profissional a ser formado se constitui como parte da classe trabalhadora, devendo com esta assumir compromisso de defesa da liberdade, luta pela ampliação e consolidação da cidadania, recusa do arbítrio e do autoritarismo, dentre outros princípios estabelecidos em sua base legal. É um projeto de formação que defende a necessária articulação entre ensino, pesquisa e extensão, entre as dimensões investigativa e interventiva que compõem a profissão, entre os núcleos de fundamentação que dão sustentação e orientação ao processo formativo. É um projeto que assume a defesa de um projeto societário que se pauta na justiça e equidade social, que acaba por acenar para a superação da sociedade de classes.

Entretanto, no cenário atual, marcado pela mercantilização do ensino superior, pela competitividade, pela multiplicação das modalidades de ensino, o projeto ético-político tecido a muitas mãos está seriamente ameaçado, visto que caminha numa direção que contraria a lógica mercantil, que almeja necessariamente o aumento das taxas de lucro. No espírito das diretrizes da ABEPSS, a formação deve ser ampla e, para isso, propiciar ao discente vivências em pesquisa, extensão, monitoria, seminários, organizações políticas, estágio supervisionado, construção de pesquisa, redação de monografia, dentre outras atividades que favoreçam uma formação generalista que habilite o egresso a fazer leitura da realidade e atuar nas diferentes expressões da questão social.

Como há nos anos 2000 uma prevalência de instituições privadas não universitárias, não se pode garantir a oferta dessa multiplicidade de experiências ao discente, visto que somente as universidades têm a obrigatoriedade de assegurar a indissociabilidade entre ensino, pesquisa e extensão. As instituições privadas não universitárias que dominam o mercado educacional têm como atividade prioritária o ensino e, em muitos casos, na modalidade a distância, onde

Como nos alerta Pereira (2013), o perfil profissional vem se empobrecendo na última década, dadas as limitações no processo formativo, onde os discentes têm pouca ou nenhuma experiência em pesquisa, iniciação científica, extensão, eventos acadêmicos, participação em movimentos estudantis, com o acompanhamento de professores com vínculos frágeis de trabalho, com sobrecarga de atividades, obrigados a exercer a multifuncionalidade, com baixa titulação e baixos salários. Além disso, como nem todas as instituições de ensino superior são filiadas à ABEPSS, as diretrizes por elas adotadas são aquelas que foram desconfiguradas pelo MEC em 2002.

Nesse sentido, torna-se possível compreender a urgência em materializar a proposta de currículo construída de maneira coletiva, crítica e política pela categoria profissional na década de 1990. O currículo de Serviço Social deve ser concretizado de forma a cumprir o compromisso éticopolítico da profissão, e não apenas como uma resposta imediata às atuais demandas do capital. 


\section{REFERÊNCIAS}

ABEPSS. Diretrizes gerais para o curso de Serviço Social. Novembro de 1996. Disponível em:< http://www.abepss.org.br/arquivos/textos/documento_201603311138166377210.pdf> Acesso em: 28 mar. 2018.

AGUIAR, Antônio Geraldo de. Filosofia e Serviço Social: das origens a Araxá. - 5.ed. - São Paulo: Cortez, Piracicaba. SP: Universidade Metodista de Piracicaba, 1995.

BRASIL. Decreto no 35.311 de 02 de abril de 1954. Regulamenta a Lei n. 1889, de 13 de junho de 1953. Disponível em: http://www2.camara.leg.br/legin/fed/decret/1950-1959/decreto-35311-2abril-1954-449402-publicacaooriginal-1-pe.html. Acesso em: 18 maio 2018.

CASTRO, Marina Monteiro de Castro e. TOLEDO, Sabrina Navarro. A reforma curricular do Serviço Social de 1982 e sua implantação na faculdade de Serviço Social da Universidade Federal de Juiz de Fora. Libertas. Revista da faculdade de serviço social - Programa de Pós-graduação em Serviço Social. v. 11. n. 2. 2012.

CFESS. Código de Ética do/a Assistente Social. Disponível em: <http://www.cfess.org.br/arquivos/CEP2011_CFESS.pdf> Acesso em: 28 mar. 2018.

Diretrizes curriculares da ABEPSS, 1999. Disponível em: <http://www.cfess.org.br/js/library/pdfjs/web/viewer.html?pdf=/arquivos/legislacao_diretrizes.p df> Acesso em: 28 mar. 2018.

IAMAMOTO, Marilda Villela. A formação acadêmico-profissional no Serviço Social brasileiro. Serviço Social \& Sociedade. - n. 120, p. 609-639, out./dez. 2014.

O Serviço Social na Contemporaneidade: trabalho e formação profissional. 26. ed. São Paulo. Cortez, 2015.

IAMAMOTO, Marilda V.; CARVALHO, Raul de. Relações sociais e Serviço Social no Brasil: esboço de uma interpretação histórico-metodológica. 38 ed. São Paulo: Cortez, 2013.

LOPES, Alice Casimiro; MACEDO, Elizabeth. Teorias de currículo. São Paulo: Cortez, 2011.

MEC. Parecer CNE/CES 492/2001 - Homologado em 9 de julho de 2001. Disponível em: <http://portal.mec.gov.br/cne/arquivos/pdf/CES0492.pdf>. Acesso em: 29 mar. 2018.

Portaria normativa $\mathrm{n}$ - 40, de 12 de dezembro de 2007. Disponível em: <http://www2.mec.gov.br/sapiens/portarias/port40.pdf>. Acesso em: 29 mar. 2018.

PEREIRA, Larissa Dahmer. Expansão dos cursos de Serviço Social na modalidade EAD no Brasil: análise da tendência à desqualificação profissional. In: PEREIRA, Larissa Dahmer; ALMEIDA, Ney Luiz Teixeira de. Serviço Social e Educação. 2 ed. Rio de Janeiro: Lumen Juris, 2013, p. 55-73 (Coleção Nova de Serviço Social).

SÁ, Jeanete Liasch Martins de. Conhecimento e Currículo em Serviço Social: análise das contradições (1936 - 1975). São Paulo. Cortez, 1995.

SACRISTÁN, José Gimeno (Org.). Saberes e incertezas sobre o currículo. Porto Alegre: Penso, 2013.

SAVIANI, Dermeval. Educação escolar, currículo e sociedade: o problema da Base Nacional Comum Curricular. Movimento: revista de educação. Ano 3, n. 4, 2016. Disponível em: http://www.revistamovimento.uff.br/index.php/revistamovimento/article/view/296. Acesso em: 15 maio 2018.

SILVA, Maria Ozanira da Silva e. Formação profissional do assistente social: inserção na realidade social e na dinâmica da profissão. 2. ed. São Paulo: Cortez, 1995. 
VASCONCELOS, Eduardo Mourão. O movimento de higiene mental e a emergência do Serviço Social no Brasil e no Rio de Janeiro. Saúde mental e Serviço Social: o desafio da subjetividade e da interdisciplinaridade. São Paulo: Cortez, 2000, p.127- 180. 